\title{
Treatment of a Fellow Doctor in a Public Sector Hospital: Ethnographic Study of Collegial Professionalism
}

\begin{abstract}
Ethics and collegiality in medical profession requires a doctor to treat fellow professional as brother and sister. Ethnography was employed to study the status of collegiality in public sector hospital, where an ailing doctor sought clinical care from a physician. The former, on account of the latter's cold reception and behaviour, reacted with his blood pressure shooting-up. The communication gap led the ailing doctor, who complied by coming to the laboratory, was perturbed, making him firstly unfit and later decided not to undergo the prescribed test. While Pakistan Medical and Dental Council have the responsibility to oversee, the undergraduate medical education and training should also lay greater emphasis on ethics in medical practice and healthy collegiality in the medical profession.
\end{abstract}

Key Words: Ethnography, Collegial Professionalism, Doctor.

\section{Introduction}

Fellow doctors are like "sisters and brothers". To this effect, physician makes declaration while entering into the medical profession. ${ }^{1}$ Ethics in medical practice require that "respect and gratitude" should be given to the seniors and teachers in the profession. ${ }^{2,3}$ There is no study undertaken in Pakistan as to how doctors coming to public sector hospitals for clinical care are treated by fellow doctors. But, an impression prevails that unethical conduct in clinical practice is widespread. ${ }^{4}$ In this treatise, we present a case of how a senior doctor was treated in a specialised public sector medical institution in Lahore.

\section{Methodology}

Ethnography is a qualitative approach to obtaining a holistic picture of study subjects with emphasis on loo- king at subject(s) in real life situations through interviewing, observation, and acting as subjects. In this case, data from a clinical setting was collected using participant observation with researcher acting as the subject. The setting included an ailing doctor, as ethnographer and active participant, and observed practice in a clinical office. Now retired, this doctor, senior to the attending physician during their internship, was the first medical director of the medical institution he had come for clinical care. Other elements of setting included physician's office, which had two parts: "a" front office, where the clients would present for assistance. Here, a clerk, after inquiring about the nature of clients' need, would guide them, inter-alia to "b" office, which is an examination room staffed by a doctor and a clerk. It is a single case, but ethnography, which uses active participant's observation, allows the results to be generalized. Confidentiality is assured by masking the different contours of the setting used in study.

\section{Findings from Participant's Observation}

The ailing doctor, who is diabetic and hypertensive, is on medication. Having had recently an episode of suspected angina, he came for medical care and approached "a" or front office. Here, the doctor introduced himself. After few questions by the clerk, he was guided to " $b$ " office, where waited also a couple of other clients. The doctor in the office would attend them by asking "who sent you?" and "what assistance is needed?" The clients' would present introductory letters, and accordingly would vary the doctors' reaction. The ailing doctor, to the aforementioned questions, introduced himself and responded, "no one sent me, and I came on my own" and that "I want to see the in-charge physician". The attending doctors asked him to wait.

After a short while, there was movement of the office staff and some others clearing the way with the 
whisper, "Saab is coming". The ailing doctor stood up and greeted the in-charge physician with warmth and great expectations, only to get a cold response, "wait and I will call you". When called in, the unwell doctor introduced and reminded his association with the specialised medical institution and that who he was? "Oh yes, I had recognized you" was the respond, and conversation shifted to the purpose of coming and the clinical history. The doctor was assisted in getting investigation, after which preliminary physical examination was performed only to note the blood pressure was 200/95mm Hg. ${ }^{5}$ Then the physician examined and advised a test, which the sick doctor did not agree and requested for an alternative. But, the physician stuck to his advice, facilitated in scheduling the test on free basis. On the scheduled day, however since blood pressure was high, the test was postponed to another date and later, not convinced with the physician's advice, the sick doctor gave that up.

\section{Discussion}

Collegial professionalism is important to foster teamwork in clinical care, and extends to managing ill and disabled colleagues. Singapore Medical Association defined professional behaviours, marking the healthy collegiality and to explicitly express, the practitioners "pledge for giving gratitude to teachers and respect to colleagues as professional brothers and sisters". ${ }^{6}$ Similar notion, following the Geneva Declaration, is inscribed in the Pakistan Medical and Dental Council's code of ethics and doctors while entering into clinical practice declare, inter-alia, "my colleagues will be like my sisters and brothers and I will pay due respect and honor to them". 7 In this case however, while the office of the physician in the specialised medical institution is tuned to respond to elites, political and bureaucratic, the professionals do not receive the respect and gratitude expected from a brother or sister in the profession. Added to that, the cold behaviour of physician led to the blood pressure of ailing colleague shooting-up.

The good collegiality required that the physician discuss the pros and cons and the alternates for clinical care. But, in this case, the treating physician displayed "professional hegemony" and was stuck to his advice. The ailing doctor, not convinced with the prescription, although complied by coming to the laboratory, reacted with high blood pressure that the test could not be performed. But, where did such an attitude of treating physician come from? The prevailing political and bureaucratic milieu in the country has brought stress for the physicians and the institutions, but may not be the sole excuse. It is also the personal attributes of suppressing dissent and avoiding discussions and the medical education and training of physicians to blame for such behavior towards their professional brothers. ${ }^{8}$

\section{Conclusion and the Way Forward}

Building and maintaining collegial relationships requires effective communication. But, in this case, it was missing: firstly at the front office, then in physician's office and the cold and hegemonic attitude of the physician was the final blow. That led to the ailing doctor losing confidence in the physician and his prescription. Such a behaviour at the top level in clinical hierarchy percolates to the lower echelons, including support staff in clinical settings, thus inculcating a culture of unhealthy collegiality in the profession. To revert and revive however, while PMDC should act, collegial professionalism should form part of undergraduate medical education and also mandatory for licensing doctors to practice. ${ }^{9}$

\section{References}

1. Declaration of Geneva available at: http://www.wma.net/en/30publications/10policies/g1/ WMA_DECLARATION-OF-GENEVA_A4_EN.pdf

2. Pakistan Medical and Dental Council Code of Ethics of Practice for Medical and Dental Practitioners, available at:

http://www.pmdc.org.pk/LinkClick.aspx?fileticket=v5 WmQYMvhz4\%3D\&tabid $=292 \& \mathrm{mid}=845$

3. Professional role of the doctor as a colleague: cultivating healthy collegiality, the forgotten pillar of medical professionalism, SMA Centre for Medical Ethics \& Professionalism.

4. http://www.pulsepakistan.com/archives/15_11_2010/ne ws1.htm

5. The ailing doctor has been on medication for several years and had taken antihypertensive dose for the day.

6. Ibid.

7. As cited above.

8. Tarin EK. Rational Prescription of Pharmaceuticals, Dissertation submitted as partial fulfillment of MA in Health Management, Planning and Policy, University of Leeds, UK, 1987.

9. Sudan Medical Council has made it mandatory for every doctor to attend a three credit hour course on professionalism in medical practice prior to appearing for licensing exam. 